\title{
Soil health conceptualization differs across key stakeholder groups in the Midwest
}

\author{
J. Wade, M.A. Beetstra, M.L. Hamilton, S.W. Culman, and A.J. Margenot
}

\begin{abstract}
Stakeholder conceptualizations of soil health inform agricultural decision-making. Currently, diverse sources of soil health knowledge have resulted in divergent conceptualizations of soil health across groups. Using a combination of mail and online surveys of corn (Zea mays L.), soybean (Glycine max [L.] Merr.), and wheat (Tritcum aestivum L.) farmers $(n=89)$; USDA Natural Resources Conservation Service (NRCS) personnel ( $n=134)$; and agricultural researchers $(n=42)$ in the Midwest; we (1) investigated how members of these groups perceived prioritization of soil health by farmers, (2) explored conceptual linkages with soil health, and (3) assessed the efficacy of soil testing methods. Farmers ranked soil health as a much higher priority (8.5/10) than NRCS personnel and researchers expected (4.9 and 5.7, respectively). While there were many areas of shared conceptualization, there were also key systematic differences across groups. Use of specific types of soil tests was positively associated with their valuation, with the exception of farmer use of soil health tests. Farmers ranked soil health tests as providing highly valued information but reported low use, suggesting barriers to adoption rather than a lack of interest. These findings have implications for both communication and research strategies for soil health.
\end{abstract}

Key words: farmer attitudes-farmer beliefs-Natural Resources Conservation Servicesoil health—soil testing

Farmers, policymakers, and the agricultural research community increasingly use the lens of soil health to conceptualize on-farm soil conservation and management. Increased discussion of soil health among these entities and in the farm press (Arbuckle 2016) illustrates that soil health knowledge is transmitted through complex networks of information exchange, rather than originating from a single source (Wick et al. 2019). Thus, there is a diverse set of stakeholders that are both consuming and/or disseminating soil health information. This is emblematic of a transition from the traditional model where knowledge is produced "by scientists, repackaged by extension officers, and launched at farmers" (Carr and Wilkinson 2005) to a more interactive, network-based model where farmers and researchers stand on more equal footing (Lubell et al. 2014). As these networks broaden, they include increasingly diverse

Received September 16, 2020; Revised January 6, 2021; Accepted April 13, 2021; Published online July $26,2021$. tionships among states of affairs, concepts, or factors (Craik 1967; Johnson-Laird 1983; Byrne and Johnson-Laird 2009). They act as a filter through which the external world is perceived, informing the assessment of risks and benefits, the assimilation of knowledge, and ultimately, decision-making. One readily identifiable indication of differing mental models of soil health is the preferred methods of assessment. Early studies of farmer perceptions of soil health suggested that farmers prefer more qualitative, holistic soil health assessments (e.g., how the ground works up with a tractor and soil smell), while researchers use more quantitative and domain-specific assessments (e.g., lab-based soil tests) (Doran and Parkin 1994; Romig et al. 1995, 1997; Ingram et al. 2010). These preferences lead to differing experiences and knowledge patterns. Farmers' soil knowledge tends to arise from experiences under ever-changing conditions whereas researchers' knowledge tends to be under more controlled conditions (Ingram et al. 2010), ultimately informing their mental models (Prager and Curfs 2016; Van Hulst et al. 2020). Attempts to integrate and reconcile quantitative soil health assessments with farmer perceptions have been met with mixed success (Andrews et al. 2003; Gruver and Weil 2007; Sprunger 2015; Lobry de Bruyn and Andrews 2016; Hargreaves et al. 2019). However, accounting for farmer mental models in extension programming and communication increases the likelihood that that advice will be implemented (Eckert and Bell 2005; Hoffman et al. 2014; Lobry de Bruyn 2019). Therefore, the blending of

Jordon Wade (corresponding author) is an assistant professor, School of Natural Resources, University of Missouri, Columbia, Missouri, previously with the Department of Crop Sciences at University of Illinois, Urbana-Champaign. Margaret A. Beetstra is a John A. Knauss Marine Policy Fellow at the National Oceanic and Atmospheric Administration, Washington, DC, previously with the School of Environment and Natural Resources at The Ohio State University, Columbus, Ohio. Matthew L. Hamilton is an assistant professor, School of Environment and Natural Resources, The Ohio State University, Columbus, Ohio. Steve W. Culman is an associate professor and state extension specialist of soil fertility, School of Environment and Natural Resources at The Ohio State University, Columbus, Ohio. Andrew J. Margenot is an assistant professor, Department of Crop Sciences, University of Illinois at Urbana-Champaign, Champaign, Illinois. 
these knowledge patterns is essential to help these stakeholders co-develop sustainable land management strategies (Ingram et al. 2010; Lobry de Bruyn et al. 2017; Van Hulst et al. 2020).

Understanding how different groups conceptualize soil health is a key step toward continued and more effective collaborations to improve agricultural sustainability. To this end, the present exploratory work focuses on three stakeholder groups within the Midwestern United States-grain crop farmers, USDA Natural Resources Conservation Service (NRCS) personnel, and agricultural researchers with soil health expertise - in order to (1) evaluate the perceived importance of soil health to farmers by each group, (2) investigate differences and similarities in conceptualizations surrounding soil health effects, and (3) determine the self-reported use and perceived value of current soil testing methods. We hypothesize that farmers will perceive soil health to be more important than NRCS personnel or agricultural researchers recognize (H1). We hypothesize that conceptualizations of soil health will differ the most between the practical knowledge of farmers and the analytical knowledge of researchers and that the NRCS personnel will occupy a middle ground between these two groups due to their role as intermediaries (H2). Finally, we expect that the three groups will have different use and value perceptions of current soil testing methods (H3). Specifically, we hypothesize that farmers' practical knowledge under variable conditions will lead them to higher usage and value placed on in-field strategies than the other two groups.

\section{Materials and Methods}

Survey Development and Implementation. We developed the soil health surveys in two stages. First, we conducted semistructured phone interviews of 30 to 60 minutes with 5 to 10 members from each group of interest. Using conventional content analysis of these interviews, we identified 19 concepts, each of which were discussed by at least two interviewees. The first two authors each coded half of the total interviews ( $n=8$ interviews each). As an inter-coder reliability check, these authors also coded half of the other author's interviews ( $n=4$ interviews each) to confirm consistency of coding. Any discrepancies were discussed and remediated to ensure accuracy and consistency. To minimize redundancy in the survey, we consolidated similar concepts, ultimately establishing six emergent concepts related to soil health: soil fertility and biological functioning, soil physical functioning, crop productivity, profitability, environmental harm, and agrochemical inputs. These broad concepts were chosen to ensure that members of all three groups had a consistent understanding of the concepts.

To describe conceptualizations of soil health, we developed a survey asking participants to relate these emergent concepts with soil health. Then in late February of 2019, we sent out surveys to 650 farmers, 1,427 NRCS employees, and 381 agricultural researchers from the greater Midwest (figure 1). We purchased the farmer survey sample from Farm Market ID (farmmarketid. com), which was comprised of corn (Zea mays L.), soybean (Glycine max [L.] Merr.), and wheat (Triticum aestivum L.) farmers that were stratified based on farm size, with equal representation of farmers with 50 to $250 \mathrm{ac}$ (20.2 to $101.2 \mathrm{ha}$ ), 500 to $1,000 \mathrm{ac}$ (202.3 to $404.6 \mathrm{ha}$ ), and $1,000+$ ac. This stratification was chosen to maximize both total area and diversity of farm sizes. We compiled NRCS personnel contacts from publicly available databases, including all employees with "soil" or "agronomy" in their position title. Agricultural researcher contacts were compiled from departmental and extension websites of 1862 land grant institutions. While not specifically a group of interest, we included USDA Agricultural Research Service (ARS) employees with a university appointment in our sample. Inclusion was based on stated research expertise where available, as well as the topic of publications from 2013 to 2018. Researchers who listed "soil health" in their research interests or who had authored publications that included the term "soil health" were included in the sample. All sample populations were drawn from Ohio, Michigan, Indiana, Illinois, Iowa, Wisconsin, Minnesota, Nebraska, North Dakota, and South Dakota. Farmer surveys were sent by mail using official The Ohio State University stationery, while NRCS and researcher surveys were sent via email. Farmers could complete the survey on paper, but all participants had the option to complete the study online. For each group, we contacted them four times across a period of six weeks. The first message (mailed to farmers, via email to NRCS employees and researchers) described the purpose of the

\section{Figure 1}

Geographic distribution of responses by state. Values are expressed as a percentage of total respondents within each group ([a] farmers, [b] USDA Natural Resources Conservation Service, and [c] researchers). Respondents were able to select multiple state(s).

(b)
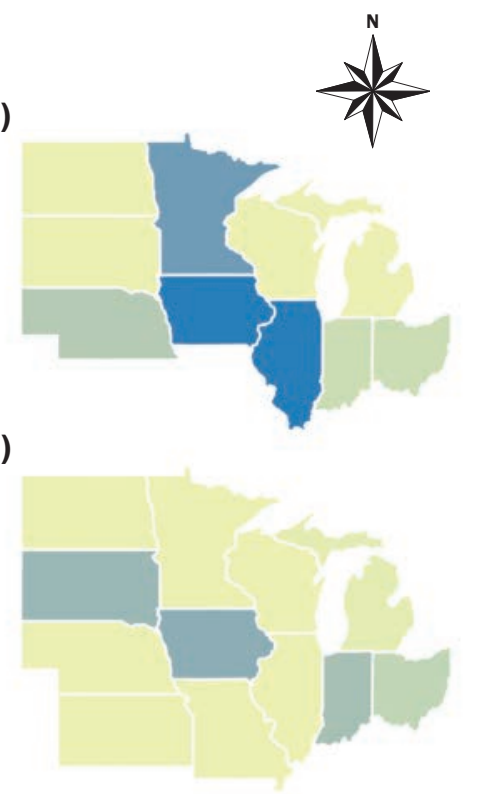

(c)

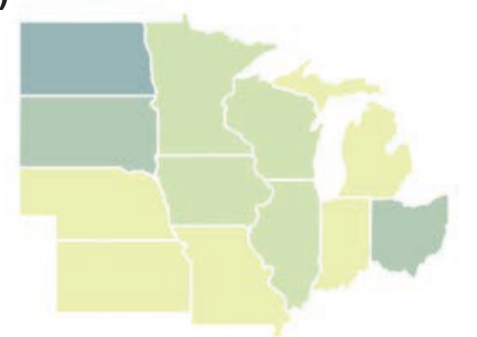

Respondents (\% of total)

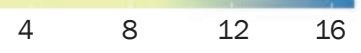

study as related to soil health and provided a link to complete it online. Two weeks later, we mailed a paper version of the survey to those farmers who had not yet completed the study online and emailed NRCS employees and researchers a reminder with the survey link. Two weeks later, we sent a reminder to farmers via a postcard and nonfarmers via email to complete the survey. Finally, two weeks later, we sent a final reminder to all groups with a mailed paper copy of the survey (farmers only) or survey link. We received complete, usable responses from 89 farmers, 134 NRCS employees, 
and 42 researchers, giving response rates of $13.7 \%, 9.4 \%$, and $11.0 \%$, respectively.

Across all three groups, the survey response rate was low. Across all groups, this may be partially attributed to the timing of the mailers. All three groups were likely preparing for or beginning spring planting as the surveys were being sent out (early spring). However, given the especially wet spring of 2019 and the delayed planting window (Morning Ag Clips 2019), this was likely less of a factor than it might be in other years. For farmers, the low response rate may be due in part to the lack of incentive attached to the survey and some issues with surveys arriving at the addresses of nonfarmers. We are likewise aware that some NRCS and researcher survey emails arrived in spam folders. Due to these challenges, it is difficult to know the true response rate for each group, although the values presented above are likely underestimations. However, given the exploratory nature of the present work and due to other reasons outlined below, we are not concerned that the low response rate impacts the results in a meaningful way.

We ascertained the representativeness of our sample in several ways. First, we found that our sample was representative of our groups of interest even though the response rates were low. We had a relatively even distribution of NRCS personnel and researcher responses across our geography of interest, though Kansas and Missouri were poorly represented in both groups (figure 1). We also compared farmer characteristics of the respondents to those of farmers from our states of interest in the 2017 Census of Agriculture (USDA NASS 2019). Farm sizes represented in our study were larger than those in the Census of Agriculture, but this is due to our strategic stratified sampling by farm size to represent more area rather than more operators. Our age distribution (table 1) was not significantly different from the National Agricultural Statistics Service-reported distribution in our surveyed states $\left(\chi^{2}=4.6, p=\right.$ 0.098; data not shown). However, our sample was slightly biased toward males, relative to the total gender breakdown of field crop primary operators within our states $\left(\chi^{2}=\right.$ $7.4, p=0.007$; data not shown). This may be partially attributable to our larger than average farm size, as males are disproportionately represented as primary operators in larger farms (USDA NASS 2019). This assessment of representativeness is particularly important because having a representative sample

\begin{tabular}{|c|c|c|c|c|}
\hline \multicolumn{2}{|c|}{ Demographics } & \multirow{2}{*}{$\begin{array}{l}\text { Farmers } \\
58.3,58 ; \\
(27,88)\end{array}$} & \multirow{2}{*}{$\begin{array}{l}\text { NRCS } \\
43.6,42 ; \\
(23,77)\end{array}$} & \multirow{2}{*}{$\begin{array}{l}\text { Researchers } \\
44.5,41.5 ; \\
(23,81)\end{array}$} \\
\hline Age & $\begin{array}{l}\text { Mean, median; } \\
(\min , \max )\end{array}$ & & & \\
\hline \multirow[t]{3}{*}{ Gender } & Male (\%) & 94.2 & 61.1 & 57.1 \\
\hline & Female (\%) & 5.8 & 37.4 & 40.5 \\
\hline & No response (\%) & 0 & 1.5 & 2.4 \\
\hline
\end{tabular}

has been shown to be more important than the response rate (Cook et al. 2000). Lastly, response rates to both mail and online surveys are declining over time (Sax et al. 2003 Stedman et al. 2019). Our response rates are comparable to several recent surveys on farmer attitudes (14.5\%) (Burli et al. 2019) and farmer economic outcomes (10\%) (Pederson et al. 2012). Thus, our challenge with a low response rate is not unique to the present study, but is broadly reflective of trends in social science research.

To better understand how each group conceptualizes soil health, we asked how respondents perceive causal links between soil health and our emergent concepts. We used multiple choice questions to ask what effect an increase in soil health has on each emergent concept, with the provided responses as "increases" (+1), "decreases" $(-1)$, or "they are not related" $(0)$. In order to differentiate between bidirectional (i.e., reciprocal relationships) and unidirectional relationships, we then asked this question in reverse: what effect an increase in each emergent concept has on soil health, with the same answer choices as before. For example, "What effect does an increase in soil health have on crop productivity?" would correspond to "What effect does an increase in crop productivity have on soil health?”Thus, our respondents indicated which concepts are affected by soil health, which we refer to as unidirectional relationships (i.e., soil health $\rightarrow$ emergent concept), and which concepts also affect soil health, which we refer to as bidirectional relationships (i.e., soil health $\leftrightarrow$ emergent concept). Respondents did not report any unidirectional relationships where an emergent concept only affected soil health (i.e., emergent concept $\rightarrow$ soil health). Our interpretation of these findings assumes that each individual accurately describes their experiences and therefore we cannot confirm with full confidence that these conceptualizations are "true" (i.e., reflect reality) or not (Moon and Blackman 2014). Accordingly, our interpretation of soil health conceptualizations is limited to communication strategies arising from those conceptualizations rather than assessing the veracity of the conceptualization.

In addition to understanding each group's conceptualizations of soil health, we were also interested in perceived soil health importance to farmers and the use and efficacy of various types of soil testing. First, we asked farmer respondents to self-identify the priority of soil health on their farm from 0 (not a priority) to 10 (highest priority). To understand how this prioritization is or is not perceived by nonfarmer groups, we also asked NRCS and researcher respondents to evaluate the degree to which they believe farmers prioritize soil health. Lastly, to determine the efficacy of soil tests, we asked all groups if they had used standard agronomic soil tests, soil health tests, or in-field tests to evaluate soils (either on their farm or for their work) in the last three years. For respondents who used a given test, we then asked them to rate the quality of information from that test, ranging from 1 (not at all helpful) to 5 (extremely helpful).

Statistical Analyses. All analyses were performed in R v1.2.5001 (R Core Team 2019) using RStudio (RStudio Team 2020). To compare the perceived farmer prioritization of soil health and farmer-reported prioritization of soil health, we used the kruskal.test( ) command in the base $\mathrm{R}$ stats package ( $\mathrm{R}$ Core Team 2019) and used dunn Test ( ) from the FSA package (Ogle et al.2020) to calculate multiplecomparison adjusted $p$-values. Comparisons were performed for each group relative to farmer reported prioritization. Graphs were constructed using ggplot2 (Wickham 2016) and ggpubr packages (Kassambara 2020).

\section{Results and Discussion}

How Important is Soil Health to Farmers? Our results indicate that soil health is a high priority to farmers in their on-farm operations, but NRCS personnel and researchers underestimate its importance to farmers (figure 2). On average, farmer respondents rated soil health 8.5 out of 10 priority on their farms (lowest reported value was a 5 ). This 


\section{Figure 2}

Perceived farmer prioritization of soil health. Dashed line represents farmer-reported prioritization of soil health. Paired comparisons of each group to farmers was performed using Kruskal-Wallis test ( $p<0.001$ for both). NRCS is the USDA Natural Resources Conservation Service.

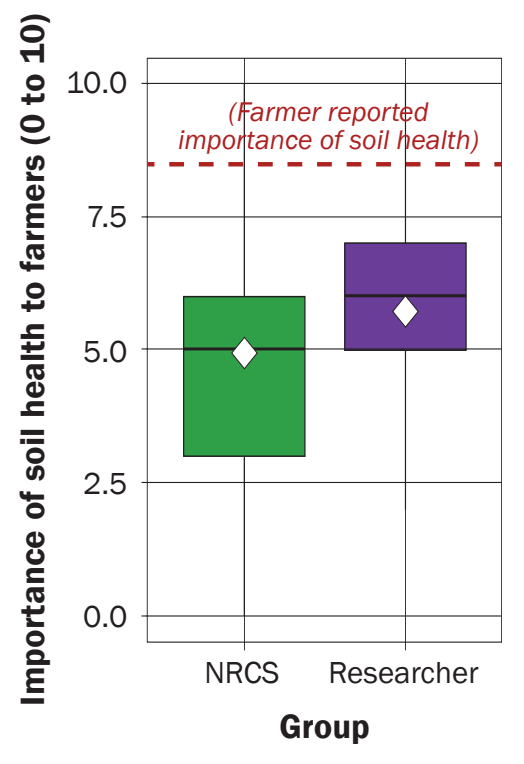

was significantly higher than what nonfarmer respondents expected $(p<0.001)$ and $\mathrm{did}$ not vary with reported frequency of interactions between nonfarmers and farmers $(p$ $>0.10$, data not shown). NRCS personnel and agricultural researchers on average estimated that farmers rank soil health at 4.9 out of 10 and 5.7 out of 10 , respectively. Thus, we confirmed our first hypothesis (H1) that the importance of soil health to farmers is likely undervalued by nonfarmer groups. The attitudes informing this systematic underestimation of the value of soil health to farmers were captured in comments from several nonfarmer respondents. One respondent said,

I think the 'how valuable is soil health to Farmers' question could be split into two questions. How valuable is it to them and how valuable should it be. I answered 3 in your survey which might be high. How valuable should it be....12!

Similarly, another respondent said,

Soil health is everything - unless we adapt and adopt [practices that increase soil health] we will lose our ability to sustainably grow crops/food. This is a MUST
DO for every farm/farmer. It needs to be our top priority.

These comments indicate both the perceived importance of soil health by the nonfarmer respondents and also their perception that farmers undervalue soil health. Other work has found similar attitudes about farmers, with nearly $90 \%$ of respondents indicating that more interest from farmers about soil health would have significant impacts within their resource management districts (Wirth-Murray and Basche 2020). Our results illustrate that farmers prioritize improving soil health to a degree not recognized by NRCS personnel or researchers. The importance of soil health may also be reflected in farmer action; one recent survey that found most Iowa farmers $(>70 \%)$ had already taken steps to improve soil health on their farms and also wanted more information (Arbuckle 2017). These previous studies and our study collectively underscore the strength of the "soil stewardship ethic" identified among farmers in the Midwest (Roesch-McNally et al. 2018). Collectively, these results demonstrate that soil health has broad, often unrecognized support.

Group-Level Conceptualizations of Soil Health. We found that several emergent concepts had high agreement across groups. Farmers, NRCS personnel, and agricultural researchers all agreed that soil health positively affected crop productivity and farm profitability (upward-pointing blue arrows in figure 3), and all groups reported bidirectional linkages between soil health and (1) soil fertility and biological functioning and (2) soil physical functioning (two-headed arrows). Bidirectional relationships (i.e., feedback loops) represent areas where conceptualizations are particularly complex and are more individualized (Levy et al. 2018). This was an unexpectedly high degree of agreement across groups, broadly refuting our hypothesis (H2). However, the complexity suggested by the bidirectional linkages demonstrates that the within-group conceptualizations can also differ substantially. One implication of this finding is that using soil health to communicate about soil biology or physical functioning is difficult, even within groups. This is evident in a lack of convergence on ways to measure biological and physical components of soil health, even within agricultural researchers (Bünemann et al. 2018; Stewart et al. 2018).
In addition to the points of agreement, we observed variation in how members of groups perceived relationships between soil health and the emergent concepts. More than 80\% of farmers perceived soil health to reduce environmental harm (downward-pointing red arrows in figure 3), whereas more than $80 \%$ of NRCS personnel and agricultural researchers not only perceived this relationship, but also indicated that environmental harm reduced soil health (figure 3). Similarly, farmer and researcher respondents reported that soil health reduced agrochemical inputs, whereas NRCS personnel additionally perceived agrochemical inputs to negatively affect soil health. Therefore, the conceptualizations of researchers were generally more closely aligned with those of farmers (five out of six emergent theme) than were the conceptualizations of NRCS employees (four out of six themes), ultimately refuting our expectation that conceptualizations by farmers and agricultural researchers would be the most distinct from one another (H2). These points of divergence represent potentially unexplored and complex areas for researchers and NRCS personnel to communicate with farmers. Therefore, communication across divergent conceptualizations of soil health requires a cautious approach until they are better understood.

Use and Value of Soil Tests. Overall, standard agronomic soil tests (e.g., pH, organic matter, and extractable nutrients) were the most commonly used type of soil test and provided the most useful information for both farmers and researchers (figure $4 \mathrm{a}$ and 4b). This was followed by in-field soil tests (e.g., shovel, by feel, etc.), which were generally less common and less useful to these groups. However, these rankings were opposite for NRCS personnel, who were most likely to use in-field tests and found those the most useful. This greater usage of in-field soil tests by NRCS personnel may reflect the duties of NRCS soil conservationists (https://www.nrcs.usda.gov/wps/portal/ $\mathrm{nrcs} /$ detail/national/careers/plan/?cid=stelprdb1085931). Although there were slight differences between groups (figure $4 \mathrm{~b}$ ), both in-field and agronomic tests were considered quite useful by all groups, often scoring at least 3.75 out of 5 . Soil health tests (e.g., Haney Test, Solvita, and Cornell Soil Health) were the least used by all groups. NRCS personnel and researchers ranked them as the least useful of the three tests, whereas farmers 


\section{Figure 3}

Group level differences in soil health. To aid in identifying areas of consensus at the group level, we have only included those relationships where $>80 \%$ of respondents agreed on the presence (i.e., \pm 1 vs. 0 ) and direction (i.e., +1 vs. -1 ) of the relationship. Bidirectional relationships with $180 \%$ consensus are included for transparency and to signal that a reported relationship exists. Blue indicates a positive relationship and red indicates a negative relationship. Darker colors indicate unidirectional relationships and light colors indicate bidirectional relationships. NRCS is the USDA Natural Resources Conservation Service.

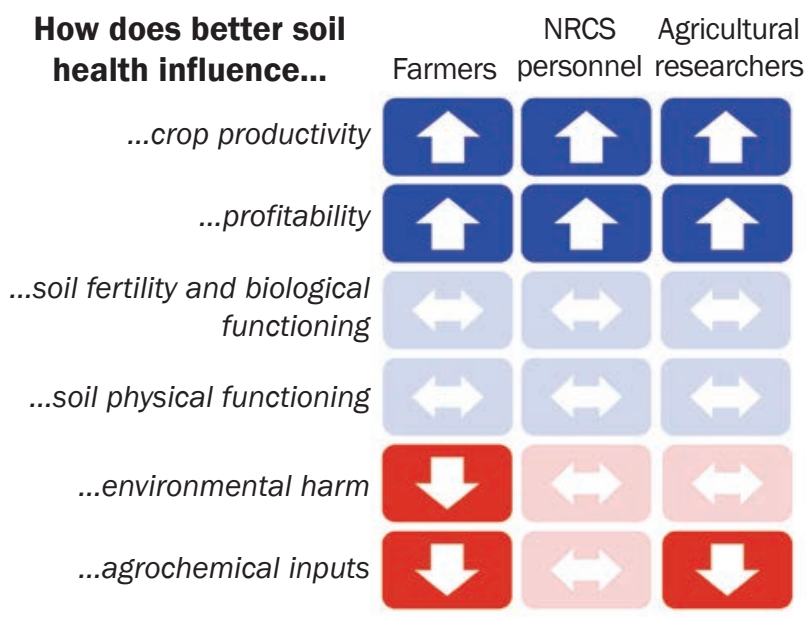

ranked them as more useful than in-field tests and less useful than agronomic tests.

Our findings support our hypothesis that groups differ in their use and valuation of various types of soil tests, although these group-level preferences differed from our hypothesized patterns (H3). Specifically, farmers used the in-field tests at similar rates to researchers and less frequently than NRCS personnel and found that information the least useful out of the three tests (figure 4b). Low farmer use and valuation of in-field soil tests differs from previous findings that farmers prefer more qualitative methods of analyzing soil (Romig et al. 1995; Karlen et al. 1997). Interestingly, the group-level usage and valuation of soil tests shows that with the exception of soil health test usage, researchers are more similar to farmers than are NRCS employees, further refuting our second hypothesis (H2).

Greater frequency of use of soil tests was generally correlated with higher reported usefulness $(r=0.96, p<0.001$; figure $4 \mathrm{c})$, with the exception of farmer responses regarding soil health tests. Farmer reports of the usefulness of soil health tests were anomalously high (3.92 out of 5) given their low usage $(14.8 \%)$. The close relationship between use and valuation is noteworthy, but it is unclear how or if this is causal. We cannot determine if respondents were more likely to use a soil test they deemed valuable or if tests were deemed more valuable because respondents used it more frequently. However, our results imply that low farmer use of soil health tests is not necessarily due to a lack of perceived utility. Other work in the Midwest has found that soil health testing is widely recognized as an essential component of agricultural management (Wirth-Murray and Basche 2020). There is a potential that farmers seeking information about soil health are more likely to use soil health tests and therefore found the information more valuable. However, we do not see any difference in the reported prioritization of soil health between farmers who use soil health tests and those who do not $(p=0.69$; data not shown). Moreover, among farmers who had used a soil health test, there was no correlation between soil health prioritization and the perceived value of information from the soil test $(r=-0.23, p=0.38$; data not shown). Therefore, we don't see any evidence of "wishful thinking" among our farmer respondents. This suggests other barriers to farmer use of soil health tests, such as availability or cost of these tests (Ranjan et al. 2019; Wirth-Murray and Basche 2020).

Limitations of Current Findings. The primary limitation of our study is the possibility that farmers who responded to the survey are the ones who value soil health the most, artificially inflating the self-evaluation of soil health importance compared to the larger Midwestern farming population. Also, some farmers may have provided a score higher than their true feelings to avoid seeming like they do not think soil health is important (i.e., social desirability bias) (Fisher 1993). However, even if this bias did occur, the large differences between groups suggest that NRCS personnel and researchers likely still undervalue the importance of soil health to farmers.

\section{Summary and Conclusions}

Using a survey of three distinct groups of stakeholders across 10 Midwestern states, we found that soil health is a potentially useful communication and framing tool. In particular, farmers prioritize soil health to a greater extent than other groups realize, although future work is needed to better understand the cause of this underestimation. While there are areas of shared conceptualizations of relationships between soil health and other production components, there are certain areas that differ systematically across groups (i.e., environmental harm and agrochemical inputs). Therefore, when communicating about soil health across groups, framing and communication strategies should be tailored to match the target group's conceptualization. Our results also highlight the value of soil health as a framework within which to discuss agronomic, environmental, and potentially economic considerations of on-farm decision-making.

As an example of how to implement these findings, if a researcher wanted to communicate with farmers about the benefits of soil health, discussing the effect of soil health on agrochemical inputs would likely be impactful. Both researchers and farmers are more likely to see this relationship as unidirectional and therefore more straightforward (figure 3). However, if a researcher used the framing of soil health to communicate with NRCS personnel about environmental harm, our results suggest that the NRCS personnel are more likely to see environmental harm as both influencing and being influenced by soil health. This reciprocal relationship could stymie communication due to individualized conceptualizations of this relationship and the high potential for unintended (yet inferred) feedback loops. That is, the audience could be inferring an additional relationship due to their differing conceptualization. For concepts with broad agreement (e.g., crop productivity and profitability), communication across groups is more likely to be successful and straightforward. Therefore, 


\section{Figure 4}

Group-level differences in (a) soil test usage and (b) the perceived value of information from each type of soil test, and (c) the relationship between soil test usage and reported value (on a scale from 1 to 5 ). Letters in (a) and (b) indicate significant differences $(p<0.05)$ in reported usage or perceived information value between groups for each type of soil test, as determined using a Kruskal-Wallis test and where "ns" indicates no significant differences between groups. Correlation and $p$-value were calculated excluding farmer soil health test data point, which was an outlier. Data in (c) are group-level means from (a) and (b). NRCS is the USDA Natural Resources Conservation Service.

(a)

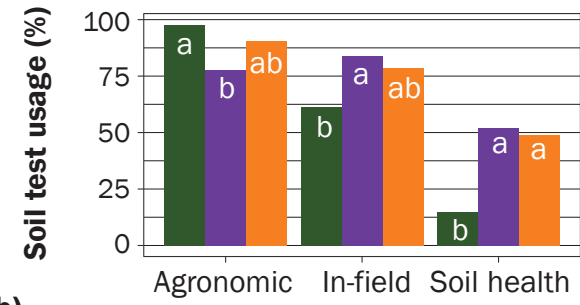

(b)

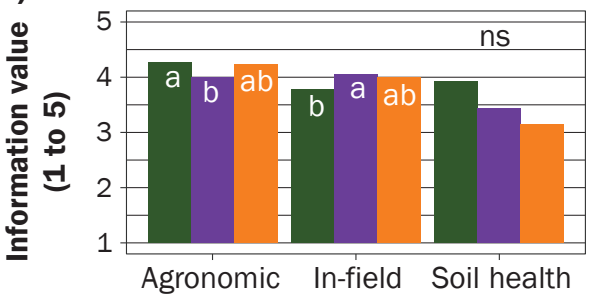

Legend

Test

Agronomic $\boldsymbol{\Delta}$ In-field $\boldsymbol{\square}$ Soil health (c)

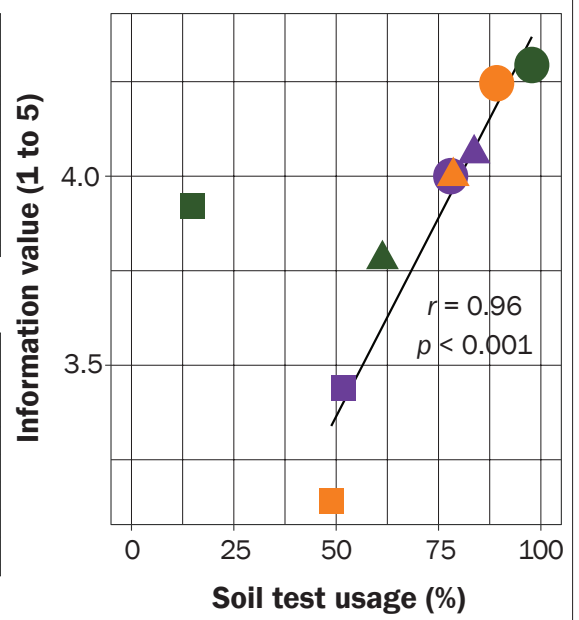

Group

Farmers NRCS Researchers careful consideration of message framing is needed to match communication goals and the specific audience (Hasling 2009; Wilson et al. 2014).

Our results also have important implications for the development and refining of soil health tests. Conceptually, farmers see a linkage between soil health and agrochemical inputs and crop productivity. However, only a handful of studies have explored these linkages using common soil health tests (Franzluebbers 2018; Yost et al. 2018; Wade et al. 2020), despite farmers demonstrating a greater willingness to implement information derived from a soil test than from nontest sources (Tao et al. 2012). Therefore, although the overall usage of soil health tests was low amongst farmers, the information farmers glean from those tests is both valuable and more likely to be implemented. This indicates that soil health testing could be effectively and broadly utilized if barriers to adoption were better understood and mitigated. An understanding of barriers to adoption will help ensure that current large-scale projects measuring and vetting soil health tests-such as the North American Project to Evaluate Soil Health Measurements currently underway by the Soil Health Institute (Norris et al. 2020) will be widely implemented by farmers.

\section{Acknowledgements}

We would like to thank all of the survey participants and preliminary interviewees who helped to develop the survey. We would also like to thank Robyn Wilson and Eric Toman (professors at The Ohio State University, Columbus, Ohio) for their assistance in developing the survey instrument. This material is based upon work that is supported by the National Institute of Food and Agriculture, USDA, under award number 2016-38640-25381 through the North Central Region Sustainable Agriculture Research and Education (SARE) program under project number GNC18-272. USDA is an equal opportunity employer and service provider. Any opinions, findings, conclusions, or recommendations expressed in this publication are those of the author and do not necessarily reflect the view of the USDA.The Ohio State University Institutional Review Board reviewed and exempted all components of this project (IDs 2018E0653, 2019E0036, and 2019E1207). We would also like to thank several anonymous reviewers and the editor for their helpful comments that have greatly improved this manuscript.

\section{Supplemental Material}

Supplementary material for this article is available in the online journal at https://doi.org/10.2489/jswc.2021.02158.

\section{References}

Andrews, S., C. Flora, J. Mitchell, and D. Karlen. 2003. Growers' perceptions and acceptance of soil quality indices. Geoderma 114(3):187-213.

Arbuckle, J.G. 2016. Iowa Farm and Rural Life Poll: 2015 Summary Report. Ames, IA: Iowa State University.

Arbuckle, J.G. 2017. Iowa Farm and Rural Life Poll: 2017 Summary Report. Ames, IA: Iowa State University.

Bünemann, E.K., G. Bongiorno, Z. Bai, R.E. Creamer, G. De Deyn, R. de Goede, L. Fleskens, V. Geissen, T.W. Kuyper, and P. Mäder. 2018. Soil quality-A critical review. Soil Biology and Biochemistry 120(2018):105-125.

Burli, P., P. Lal, B. Wolde, S. Jose, and S. Bardhan. 2019. Factors affecting willingness to cultivate switchgrass: Evidence from a farmer survey in Missouri. Energy Economics 80(2019):20-29

Byrne, R.M., and P.N. Johnson-Laird. 2009. 'If' and the problems of conditional reasoning. Trends in Cognitive Sciences 13(7):282-287.

Carr, A., and R. Wilkinson. 2005. Beyond participation: Boundary organizations as a new space for farmers and scientists to interact. Society and Natural Resources 18(3):255-265.

Cook, C., F. Heath, and R.L. Thompson. 2000. A metaanalysis of response rates in web-or internet-based surveys. Educational and psychological measurement 60(6):821-836.

Craik, K.J.W. 1967. The Nature of Explanation. 1st Updated. Cambridge, UK: Cambridge University Press.

Doran, J.W., and T.B. Parkin. 1994. Defining and assessing soil quality. Defining soil quality for a sustainable environment 35(1994):1-21.

Eckert, E., and A. Bell. 2005. Invisible force: Farmers' mental models and how they influence learning and actions. Journal of Extension 43(3):1-10.

Fisher, R.J. 1993. Social desirability bias and the validity of indirect questioning. Journal of Consumer Research 20(2):303-315.

Franzluebbers, A.J. 2018. Soil-test biological activity with the flush of $\mathrm{CO}_{2}$ : III. Corn yield responses to applied nitrogen. Soil Science Society of America Journal 82(3):708-721.

Gruver, J.B., and R.R.Weil. 2007. Farmer perceptions of soil quality and their relationship to management-sensitive soil parameters. Renewable Agriculture and Food Systems (2007):271-281.

Hargreaves, S.K., P. DeJong, K. Laing, T. McQuail, and L.L. Van Eerd. 2019. Management sensitivity, repeatability, and consistency of interpretation of soil health indicators on organic farms in southwestern Ontario. Canadian Journal of Soil Science 99(4):508-519.

Hasling, J. 2009. The Audience, the Message, the Speaker. New York: McGraw-Hill Higher Education. 
Hoffman, M., M. Lubell, and V. Hillis. 2014. Linking knowledge and action through mental models of sustainable agriculture. Proceedings of the National Academy of Sciences 111(36):13016-13021.

Ingram, J., P. Fry, and A. Mathieu. 2010. Revealing different understandings of soil held by scientists and farmers in the context of soil protection and management. Land Use Policy 27(1):51-60.

Johnson-Laird, P.N. 1983. Mental models:Towards a cognitive science of language, inference, and consciousness. Cambridge, MA: Harvard University Press.

Karlen, D., M. Mausbach, J. Doran, R. Cline, R. Harris, and G. Schuman. 1997. Soil quality: A concept, definition, and framework for evaluation (a guest editorial). Soil Science Society of America Journal 61(1):4-10.

Kassambara, A. 2020. ggpubr: "ggplot2" Based Publication Ready Plots.

Levy, M.A., M.N. Lubell, and N. McRoberts. 2018. The structure of mental models of sustainable agriculture. Nature Sustainability 1(8):413-420.

Lobry de Bruyn, L.A. 2019. Learning opportunities: Understanding farmers' soil testing practice through workshop activities to improve extension support for soil health management. Soil Use and Management 35(1):128-140.

Lobry de Bruyn, L., and S. Andrews. 2016. Are Australian and United States farmers using soil information for soil health management? Sustainability 8(4):304.

Lobry de Bruyn, L., A. Jenkins, and S. Samson-Liebig. 2017. Lessons learnt: Sharing soil knowledge to improve land management and sustainable soil use. Soil Science Society of America Journal 81(3):427-438.

Lubell, M., M. Niles, and M. Hoffman. 2014. Extension 3.0: Managing agricultural knowledge systems in the network age. Society \& Natural Resources 27(10):1089-1103.

Moon, K., and D. Blackman. 2014. A guide to understanding social science research for natural scientists. Conservation Biology 28(5):1167-1177.

Morning Ag Clips. 2019, May 2. Slow corn progress across U.S. Greenwich, NY: Morning Ag Clips.

Norris, C.E., G. Mac Bean, S.B. Cappellazzi, M. Cope, K.L. Greub, D. Liptzin, E.L. Rieke, P.W. Tracy, C.L. Morgan, and C.W. Honeycutt. 2020. Introducing the North American project to evaluate soil health measurements. Agronomy Journal 112(4):3195-3215.

Ogle, D.H., P. Wheeler, and A. Dinno. 2020. FSA: Fisheries Stock Analysis. https://github.com/droglenc/FSA.

Pederson, G., W. Chung, and R. Nel. 2012. Microeconomic impacts of a state-funded farmer loan program. Agricultural Finance Review 72(1).

Prager, K., and M. Curfs. 2016. Using mental models to understand soil management. Soil Use and Management 32(1):36-44.

R Core Team. 2019. R: A language and environment for statistical computing.Vienna, Austria: R Foundation for Statistical Computing.
Ranjan, P., S.P. Church, K. Floress, and L.S. Prokopy. 2019 Synthesizing conservation motivations and barriers: What have we learned from qualitative studies of farmers' behaviors in the United States? Society \& Natural Resources 32(11):1171-1199.

Roesch-McNally, G., J.G. Arbuckle, and J.C. Tyndall. 2018. Soil as social-ecological feedback: Examining the "ethic" of soil stewardship among Corn Belt farmers. Rural Sociology 83(1):145-173.

Romig, D.E., M.J. Garlynd, and R.F. Harris. 1997. Farmerbased assessment of soil quality: A soil health scorecard. Methods for Assessing Soil Quality 49(1997):39-60.

Romig, D.E., M.J. Garlynd, R.F. Harris, and K. McSweeney. 1995. How farmers assess soil health and quality. Journal of Soil and Water Conservation 50(3):229-236

RStudio Team. 2020. RStudio: Integrated Development for R. Boston, MA: RStudio, Inc.

Sax, L.J., S.K. Gilmartin, and A.N. Bryant. 2003. Assessing response rates and nonresponse bias in web and paper surveys. Research in Higher Education 44(4):409-432.

Sprunger, C.D. 2015. Root production and soil carbon accumulation in annual, perennial, and diverse cropping systems. East Lansing, MI: Michigan State University. https://lter.kbs.msu.edu/pub/3517.

Stedman, R.C., N.A. Connelly, T.A. Heberlein, D.J. Decker, and S.B. Allred. 2019. The end of the (research) world as we know it? Understanding and coping with declining response rates to mail surveys. Society \& Natural Resources 32(10):1139-1154.

Stewart, R.D., J. Jian, A.J. Gyawali, W.E. Thomason, B.D. Badgley, M.S. Reiter, and M.S. Strickland. 2018. What we talk about when we talk about soil health. Agricultural \& Environmental Letters 3(1).

Tao, H., T.F. Morris, B. Bravo-Ureta, R. Meinert, and J. Neafsey. 2012. Nutrient applications reported by farmers compared with performance-based nutrient management plans. Agronomy Journal 104(2):437-447.

USDA NASS (National Agricultural Statistics Service) 2019. 2017 Census of Agriculture. Washington, DC: USDA NASS.

Van Hulst, F., R. Ellis, K. Prager, and J. Msika. 2020. Using co-constructed mental models to understand stakeholder perspectives on agro-ecology. International Journal of Agricultural Sustainability 18(2):172-195.

Wade, J., S.W. Culman, J.A. Logan, H. Poffenbarger, M.S Demyan, J.H. Grove, A.P. Mallarino, J.M. McGrath, M. Ruark, and J.R. West. 2020. Improved soil biological health increases corn grain yield in $\mathrm{N}$ fertilized systems across the Corn Belt. Scientific Reports 10(1):1-9.

Wick, A.F., J. Haley, C. Gasch, T. Wehlander, L. Briese, and S. Samson-Liebig. 2019. Network-based approaches for soil health research and extension programming in North Dakota, USA. Soil Use and Management 35(1):177-184.

Wickham, H. 2016. ggplot2: elegant graphics for data analysis. New York: Springer-Verlag.
Wilson, R.S., G. Howard, and E.A. Burnett. 2014. Improving nutrient management practices in agriculture: The role of risk-based beliefs in understanding farmers' attitudes toward taking additional action. Water Resources Research 50(8):6735-6746.

Wirth-Murray, M., and A. Basche. 2020. Stimulating soil health within Nebraska's Natural Resources Districts. Journal of Soil and Water Conservation 75(4):88A-93A. https://doi.org/10.2489/jswc.2020.0512A.

Yost, M.A., K.S. Veum, N.R. Kitchen, J.E. Sawyer, J.J. Camberato, P.R. Carter, R.B. Ferguson, F.G. Fernández, D.W. Franzen, and C.A. Laboski. 2018. Evaluation of the Haney Soil Health Tool for corn nitrogen recommendations across eight Midwest states. Journal of Soil and Water Conservation 73(5):587-592. https:// doi.org/10.2489/jswc.73.5.587. 